\title{
Distribution of ventilation and frequency-dependence of dynamic lung compliance
}

\author{
S. T. CHIA N G \\ Pulmonary Laboratory, Department of Medicine, National Defence Medical Centre, Taipei, Taiwan, \\ Republic of China; Pulmonary Laboratory, Department of Medicine, Taiwan Veterans \\ General Hospital, Taipei, Taiwan, Republic of China; and Department of \\ Internal Medicine, Yale University School of Medicine, New Haven, Connecticut, U.S.A.
}

Lung components were analysed and dynamic pulmonary compliance was determined in 10 young healthy female subjects and seven adult male patients with bronchial obstruction. In normal subjects with a single ventilatory component (by multiple breath nitrogen washout method) a change of respiratory frequency did not affect dynamic lung compliance. Other normal subjects had two ventilatory components; in them and in the patients with bronchial obstruction, an increase of respiratory frequency decreased dynamic pulmonary compliance. A change of respiratory rate caused a greater change of dynamic lung compliance in the patients with bronchial obstruction than in normal subjects with two-component lungs. The results indicate that frequency-dependence of compliance and non-uniform distribution of inspired gas are caused by a similar mechanism. Inequality of regional time constants may be an important factor in this mechanism. The data also show that a decrease of dynamic lung compliance by more than $20 \%$ at a respiratory rate of 80 to 100 breaths/minute may be indicative of lung disease with obstruction.

The relationship between frequency-dependence of lung compliance and the distribution of inspired gas in the lungs has been the subject of several previous studies (Otis et al., 1956; Defares and Donleben, 1960 ; Ingram and Schilder, 1968). Frequency-dependence of compliance occurs in patients with airway obstruction (Channin and Tyler, 1962 ; Takishima et al., 1967 ; Grimby et al., 1968 ; Mead, 1969a ; Woolcock, Vincent, and Macklem, 1969). Its occurrence in healthy persons is considered to be undetectable between the frequency of 0 and 90 breaths/minute (Mead, 1969a). Otis et al. (1956) failed to find the phenomenon in their healthy subjects; others (Butler, White, and Arnott, 1957 ; Defares and Donleben, 1960 ) found it in only a few normal persons. Mills, Cumming, and Harris (1963) found it in all their subjects but only during breathing at low lung volume levels. Albright and Bondurant (1965) found frequency-dependent compliance in all their nine normal subjects. Frank, Mead, and Ferris (1957) studied nine healthy elderly adults and consistently found a small decrease in pulmonary compliance with increasing frequency. In nine normal young adults, Peslin, Saunier,
Lacoste, and Sadoul (1961), found mean elastance of $4 \cdot 2,5 \cdot 31,7 \cdot 1$, and $11 \mathrm{~cm} \mathrm{H}_{2} \mathrm{O} /$ litre at 0 to 10,10 to 20,20 to 30 , and $>30$ breaths/min respectively. In the data published recently by Woolcock et al. (1969), four of their normal subjects showed a more than $10 \%$ decrease of pulmonary compliance when respiratory frequency was increased.

According to the theory of Otis et al. (1956), frequency-dependence of compliance implies the presence of at least two lung compartments with different time constants. They pointed out that this does not imply that ventilation is uniformly or non-uniformly distributed at a given breathing rate; however, it does imply that the distribution of ventilation alters with increasing breath rate. However, if the factors which lead to nonuniformity of mechanical time constants are the same ones which cause non-uniformity of ventilation, there ought to be some relationship between the finding of non-uniform gas distribution and that of frequency-dependence of compliance. In healthy persons, the washout of nitrogen from the lung during oxygen breathing behaves either according to a single exponential 
function or according to the sum of two exponential functions (Fowler, Cornish, and Kety, 1952 ; Briscoe and Cournand, 1959; Bouhuys, 1963). The latter finding is presumably evidence of nonuniform distribution of inspired gas, and indicates the existence of at least two different unequal ventilation/lung volume ratios in the lungs. Using this definition of non-uniform ventilation, we have attempted to demonstrate a relation between non-uniform ventilation and frequency-dependence of compliance in healthy subjects and patients with airway obstruction.

\section{SUBJECTS AND METHODS}

The 10 healthy subjects in the present study were junior high school girl students, were non-smokers, and were randomly selected from a group of 102 healthy female subjects who took part in a study on nitrogen washout curves. In addition, seven patients with clinical evidence of obstructive lung disease were studied. Some of their physical characteristics and the results of standard lung function tests are shown in Table I.

The nitrogen washout method, with graphical analysis according to Fowler et al. (1952) and endtidal sampling according to Bouhuys, Hagstam, and Lundin (1956), was used to measure the distribution of inspired gas in the lungs. Nitrogen washout was continued for 7 minutes. The flow and negative pressure used for sampling were kept constant. Ventila- tion was measured by a kymograph attached to a Tissot spirometer. Subjects who showed variation of ventilation during the experiment were excluded from the study. To obtain a final alveolar nitrogen concentration a forced expiration was made at the end of each run. This value was used in calculating the functional residual capacity (FRC) (Darling, Cournand, and Richards, 1940) and the index of intrapulmonary mixing (IIPM) (Darling et al., 1940).

Lung compliance was obtained from recordings of transpulmonary pressure, using an oesophageal balloon, air flow rate and tidal volume (Mead and Whittenberger, 1953). In testing the frequencyresponse of apparatus used in this study, the presence of the instrumental phase shift described in the paper of Mills et al. (1963) was followed, and our results were quite similar to theirs. Frequencies up to 100 minute and flow rates covering the range used under experimental conditions were shown to produce no phase shift. Volumes were integrated from flow signals. It was demonstrated that the delay and phase shift within the integrator were unmeasurable by the technique used. Air flow rate was measured with a screen type pneumotachograph; tidal volume was obtained by integration of flow. All three signals (pressure, flow, and volume) were recorded on a photographic recorder, $v$. time. Dynamic lung compliance $\left(C_{d y n}(1)\right)$ was first measured at the spontaneous resting breathing rate, and then at rates of $40,60,80$, and 100 breaths per minute. During the runs at increased breath rate, tidal volume was visually monitored on an oscilloscope by the subject and was similar to the measurements obtained at a

T A B LE I

PHYSICAL CHARACTERISTICS OF EACH SUBJECT AND MEASUREMENTS OF VENTILATORY FUNCTION

\begin{tabular}{|c|c|c|c|c|c|c|c|c|c|c|c|c|}
\hline Subject & Sex & $\begin{array}{l}\text { Age } \\
(y r)\end{array}$ & $\underset{(\mathrm{cm})}{\mathrm{Ht}}$ & $\begin{array}{l}\text { Wt } \\
(\mathbf{k g})\end{array}$ & $\begin{array}{l}\text { BSA } \\
\left(\mathrm{m}^{2}\right)\end{array}$ & $\begin{array}{r}\text { VC } \\
\text { Pred. }\end{array}$ & $\begin{array}{l}\text { rPS) } \\
\text { Obs. }\end{array}$ & $\begin{array}{c}\text { FRC } \\
\text { Pred. }\end{array}$ & $\begin{array}{l}\text { TPS) } \\
\text { Obs. }\end{array}$ & $\begin{array}{c}\text { MVV (I) } \\
\text { Pred. }\end{array}$ & $\begin{array}{l}\text { BTPS) } \\
\text { Obs. }\end{array}$ & $\underset{\left(\% \mathbf{N}_{2}\right)}{\text { IIPM }}$ \\
\hline $\begin{array}{c}\text { Normal sub } \\
1 \\
2 \\
3 \\
4 \\
\text { Mean } \\
\text { S.D. }\end{array}$ & $\begin{array}{l}\text { s with } \\
\text { F } \\
\text { F } \\
\text { F } \\
\text { F }\end{array}$ & $\begin{array}{l}\text { igle con } \\
15 \\
15 \\
15 \\
14 \\
14 \cdot 75 \\
0.5\end{array}$ & $\begin{array}{l}\text { onent lut } \\
145 \\
153 \\
159 \\
151 \\
152 \\
5.8\end{array}$ & $\begin{array}{l}s \\
40 \\
46 \\
45 \\
41 \\
43 \\
2.94\end{array}$ & $\begin{array}{l}1.23 \\
1.36 \\
1.39 \\
1.29 \\
1.32 \\
0.07\end{array}$ & $\begin{array}{l}2.35 \\
2 \cdot 71 \\
2.00 \\
2.61 \\
2.67 \\
0.27\end{array}$ & $\begin{array}{l}1 \cdot 92 \\
2 \cdot 10 \\
2 \cdot 78 \\
2 \cdot 37 \\
2 \cdot 29 \\
0 \cdot 37\end{array}$ & $\begin{array}{l}1.52 \\
1.72 \\
1.89 \\
1.67 \\
1.70 \\
0.15\end{array}$ & $\begin{array}{l}2.13 \\
1.21 \\
1.33 \\
1.40 \\
1.52 \\
0.42\end{array}$ & $\begin{array}{l}75 \\
97 \\
84 \\
86 \cdot 2 \\
9 \cdot 2\end{array}$ & $\begin{array}{l}101 \\
80 \\
80 \\
87 \\
12 \cdot 1\end{array}$ & $\begin{array}{l}1 \cdot 85 \\
2 \cdot 20 \\
1 \cdot 25 \\
1 \cdot 10 \\
1 \cdot 60 \\
0 \cdot 51\end{array}$ \\
\hline $\begin{array}{c}\text { Normal sub } \\
5 \\
6 \\
7 \\
8 \\
9 \\
10 \\
\text { Mean } \\
\text { S.D. }\end{array}$ & $\begin{array}{l}\text { s wit } \\
\text { F } \\
\text { F } \\
\text { F } \\
\text { F } \\
\text { F } \\
\text { F }\end{array}$ & $\begin{array}{l}\text { uble co } \\
14 \\
15 \\
14 \\
14 \\
14 \\
13 \\
14 \\
0.6\end{array}$ & $\begin{array}{l}\text { onent lu } \\
159 \\
153 \\
152 \\
157 \\
158 \\
154 \\
155.4 \\
2.6\end{array}$ & $\begin{array}{l}s \\
58 \\
40 \\
42 \\
42 \\
44 \\
44 \\
45 \\
6.54\end{array}$ & $\begin{array}{l}1.55 \\
1.28 \\
1.30 \\
1.34 \\
1.35 \\
1.38 \\
1.37 \\
0.10\end{array}$ & $\begin{array}{l}3.00 \\
2.71 \\
2.66 \\
2.90 \\
2.93 \\
2.75 \\
2.82 \\
0.14\end{array}$ & $\begin{array}{l}3 \cdot 00 \\
2 \cdot 30 \\
2.61 \\
2.92 \\
2.64 \\
2.65 \\
2.69 \\
0.25\end{array}$ & $\begin{array}{l}1.89 \\
1.72 \\
1.70 \\
1.84 \\
1.85 \\
1.75 \\
1.79 \\
0.08\end{array}$ & $\begin{array}{l}1.47 \\
1.91 \\
2.24 \\
2.30 \\
1.98 \\
1.52 \\
1.90 \\
0.35\end{array}$ & $\begin{array}{c}97 \\
88 \\
86 \\
93 \\
-. \\
\overline{91} \cdot 0 \\
4 \cdot 97\end{array}$ & $\begin{array}{r}80 \\
84 \\
111 \\
105 \\
- \\
\overline{95} \cdot 0 \\
15 \cdot 3\end{array}$ & $\begin{array}{l}1 \cdot 40 \\
2 \cdot 20 \\
2 \cdot 60 \\
1 \cdot 30 \\
1 \cdot 80 \\
2 \cdot 20 \\
1 \cdot 92 \\
0 \cdot 51\end{array}$ \\
\hline $\begin{array}{c}\text { Patients wi } \\
11 \\
12 \\
13 \\
14 \\
15 \\
16 \\
17 \\
\text { Mean } \\
\text { S.D. }\end{array}$ & $\begin{array}{l}\text { ronch } \\
\mathbf{M} \\
\mathbf{M} \\
\mathbf{M} \\
\mathbf{M} \\
\mathbf{M} \\
\mathbf{M} \\
\mathbf{M}\end{array}$ & $\begin{array}{l}\text { obstruct } \\
26 \\
21 \\
41 \\
25 \\
39 \\
14 \\
56 \\
31 \cdot 7 \\
14 \cdot 4\end{array}$ & $\begin{array}{l}n \\
167 \\
163 \\
163 \\
179 \\
160 \\
162 \\
162 \\
165 \\
6 \cdot 17\end{array}$ & $\begin{array}{l}56 \\
48 \\
49 \\
66 \\
46 \\
50 \\
55 \\
52 \cdot 8 \\
3 \cdot 2\end{array}$ & $\begin{array}{l}1.56 \\
1.45 \\
1.46 \\
1.77 \\
1.40 \\
1.46 \\
1.53 \\
1.51 \\
0.13\end{array}$ & $\begin{array}{l}4 \cdot 53 \\
4 \cdot 50 \\
4 \cdot 05 \\
5 \cdot 17 \\
3 \cdot 91 \\
3 \cdot 58 \\
3.61 \\
4 \cdot 19\end{array}$ & $\begin{array}{l}3.25 \\
3.00 \\
3.42 \\
3.66 \\
2.36 \\
2.72 \\
2.00 \\
2.92 \\
0.59\end{array}$ & $\begin{array}{l}2 \cdot 36 \\
2 \cdot 27 \\
2 \cdot 27 \\
2 \cdot 72 \\
2 \cdot 16 \\
2 \cdot 22 \\
2 \cdot 23 \\
2 \cdot 32\end{array}$ & $\begin{array}{l}3 \cdot 30 \\
3 \cdot 68 \\
4 \cdot 50 \\
3 \cdot 35 \\
3 \cdot 10 \\
2 \cdot 64 \\
4 \cdot 50 \\
3 \cdot 58 \\
0 \cdot 70\end{array}$ & $\begin{array}{l}167 \\
171 \\
145 \\
184 \\
142 \\
100 \\
122 \\
147 \cdot 3\end{array}$ & $\begin{array}{l}98 \cdot 7 \\
74 \cdot 5 \\
72 \cdot 5 \\
66 \cdot 8 \\
38 \cdot 0 \\
63 \cdot 3 \\
62 \cdot 0 \\
60 \cdot 8 \\
24 \cdot 0\end{array}$ & $\begin{array}{l}3 \cdot 80 \\
3 \cdot 70 \\
3 \cdot 60 \\
5 \cdot 20 \\
2 \cdot 60 \\
4 \cdot 20 \\
7 \cdot 20 \\
4 \cdot 29 \\
1 \cdot 48\end{array}$ \\
\hline
\end{tabular}

BSA = body surface area; VC $=$ vital capacity; $F R C=$ functional residual capacity; MVV $=$ maximal voluntary ventilation; IIPM = index of intrapulmonary mixing. For subjects 1 to 10 , predicted values of VC and FRC were based on the equation derived by Zapletal $e t$ al. (1969).
MVV was based on the report of Ferris and Smith (1953). Predicted values of VC, FRC, and MVV for subjects 11 to 17 were based on Kory et al. (1961). 
resting breathing rate. Individual values for $\mathbf{C}_{d y n}(1)$ were calculated from the mean of at least 10 respiratory cycles. Immediately before each run, the subject was asked to inhale fully to total lung capacity and then to exhale to normal resting level to eliminate any effect of lung volume history.

In all subjects, nitrogen washout and compliance studies were done during the same session (Lyons and Chiang, 1966) and with the subject in the same position (Chiang and Lyons, 1966), i.e., seated in the erect position and with the hands on a stand. The standard spirometric tests (Kory, Callahan, Boren, and Syner, 1961) were done with a 13.5 litre Collins spirometer.

\section{RESULTS}

HEALTHY SUBJECTS In four subjects, the nitrogen washout graphs resulted in a single exponential function within the limits of accuracy of the graphic analysis; six others had nitrogen washout graphs which could be described as the sum of two or three exponential functions. At resting breathing rates values for $\mathrm{C}_{\mathrm{dyn}}(1)$ were similar in both groups. However, at high rates, compliance decreased in the subjects with double exponential washout curves (Table II, Fig. 1B), whereas it remained nearly constant throughout the range of breathing rates in the four subjects whose nitrogen washout curves were single exponential function (Table II, Fig. 1A).

PATIENTS WITH AIRWAY OBSTRUCTION In patients with bronchial obstruction, graphic analyses of nitrogen washout resulted in two or three exponential functions. In these patients, $C_{\text {dyn }}(1)$ decreased with increasing breathing rate, and the extent of the decrease was larger than in the healthy female subjects with double exponential washout curves (Table II, Fig. IC).

\section{DISCUSSION}

An increase of breathing rate did not affect dynamic lung compliance in subjects whose nitrogen washout curves were described by a single exponential function. On the other hand, subjects whose nitrogen washout curves consisted of the sum of two exponential functions all had a decrease of dynamic lung compliance with increasing breathing rate. This was true for healthy girls as well as for the patients with bronchial obstruction. The latter group had a larger degree of non-uniform distribution of inspired gas. Indices of intrapulmonary gas mixing (Darling et al., 1940) were greater than $2.5 \%$ in all patients (Table I), and dynamic lung com-
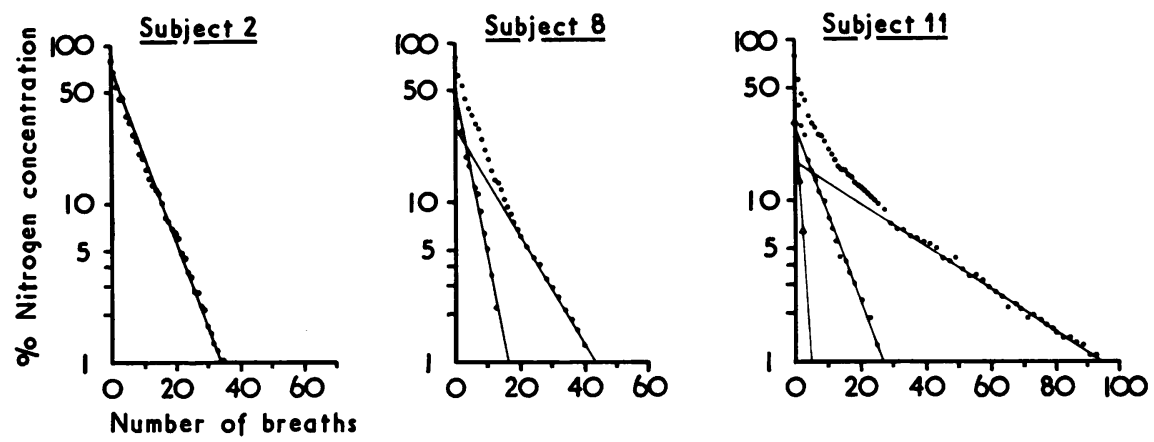

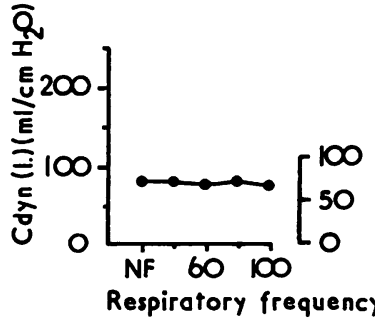

(A)

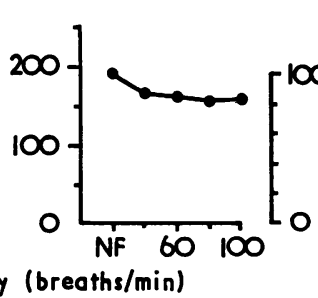

(B)

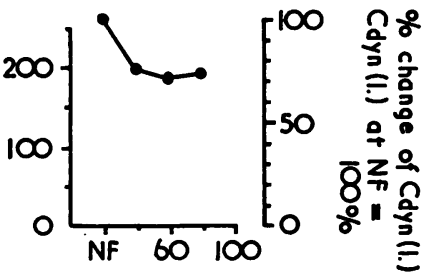

(C)

FIG. 1. Multiple breath nitrogen washout curve and dynamic lung compliance at different respiratory frequencies in $(A)$ normal subject with single component lung; $(B)$ normal subject with double component lung; and $(C)$ patient with bronchial obstruction. 
S. T. Chiang

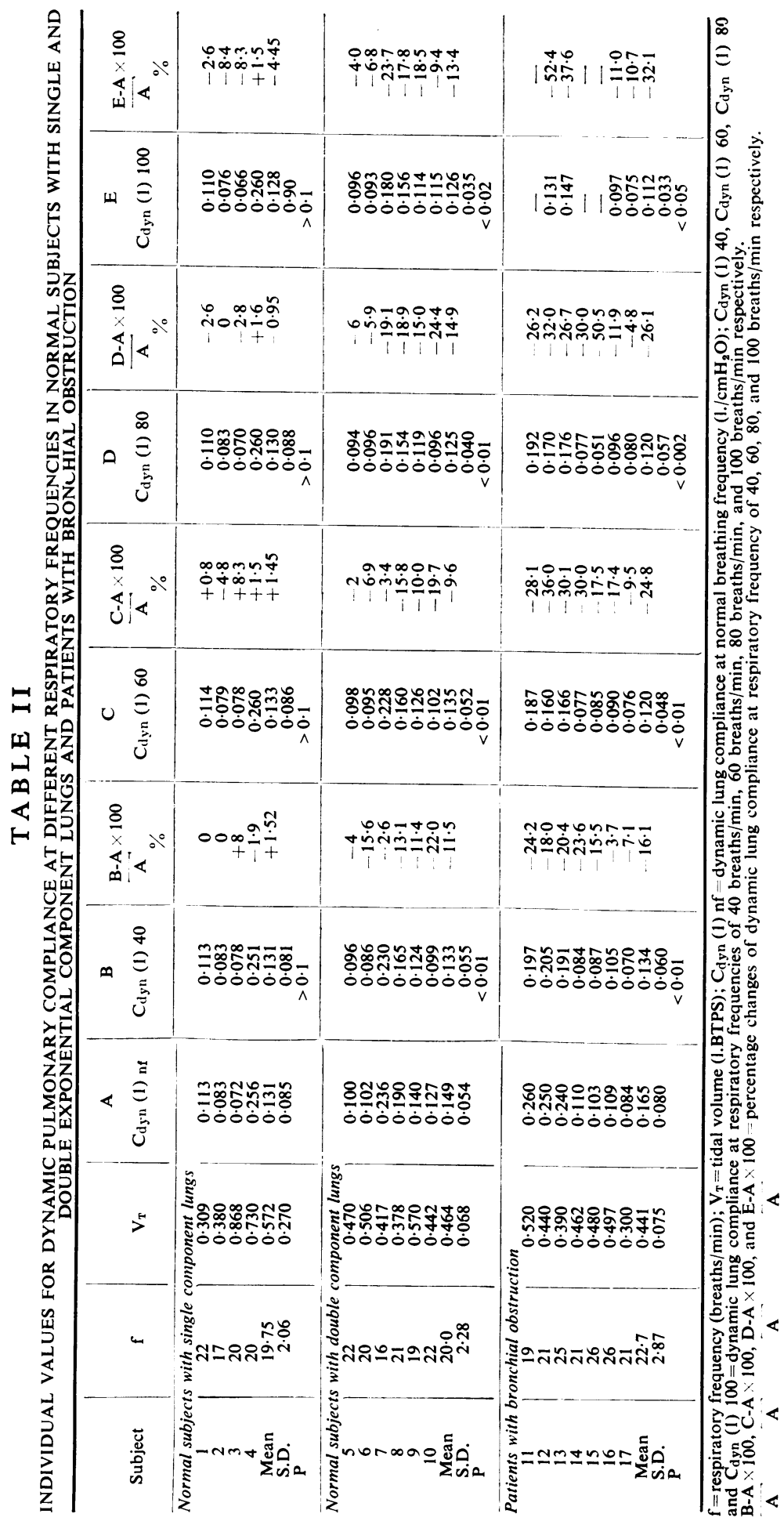


pliance decreased more with increasing rate than in the normal subjects with double exponential washout curves (Fig. 2).

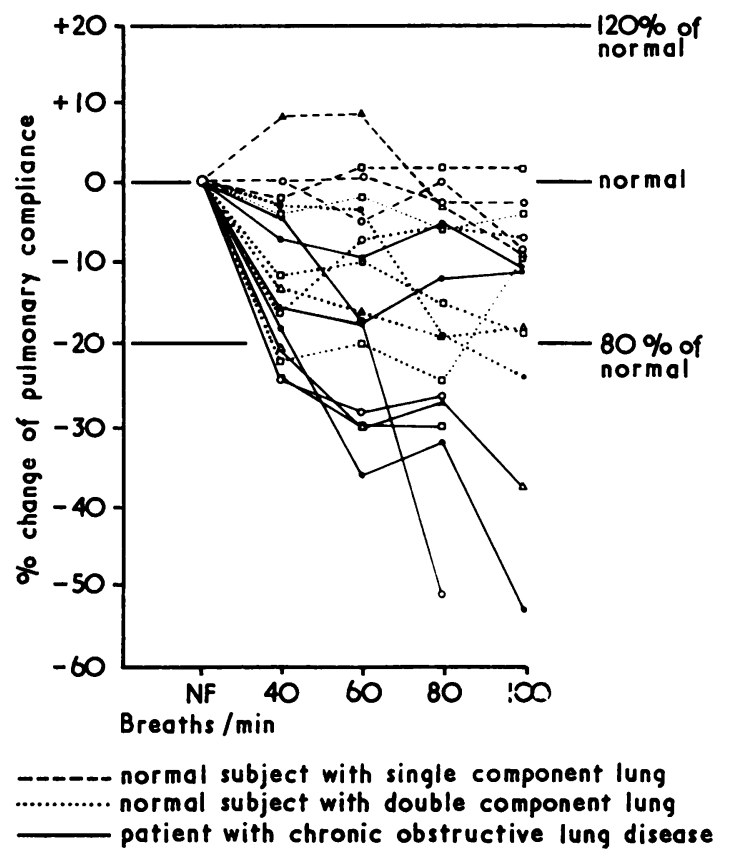

FIG. 2. Percentage changes of dynamic lung compliance at different respiratory frequencies in normal subjects and in patients with obstructive lung disease.

A decrease of lung compliance with increasing breathing rates has been explained by Otis et al. (1956) on the assumption that such lungs consist of a number of pathways from the alveo'i to the airway opening with an inequality of time constants. The present data suggest that lungs which behave in this way also demonstrate non-uniformity of the distribution of inspired gas at rest, i.e. different ventilation/lung volume ratios. This supports the notion that the mechanism which causes regionally unequal time constants, i.e., local differences in compliance and/or resistance in different lung units, is also responsible for regionally differing ventilation/volume ratios. It has recently been suggested by Cumming, Crank, Horsfield, and Parker (1966) that stratified inhomogeneity of gas in peripheral lung units may contribute more to non-uniform distribution of inspired gas than has been thought previously. However, if one assumes that, in the present subjects, particularly in healthy ones, non-uniform distribution was the result of the mechanism of 'stratified inhomogeneity', it is difficult to explain why there should be a correlation between nonuniform gas distribution and frequency-dependence of compliance.

Defares and Donleben (1960) found four out of 100 normal subjects in whom lung compliance was frequency-dependent, and in these same four subjects, nitrogen washout was by a single exponential washout curve. This appears, therefore, to be a relatively rare finding. It is quite clear that in individual cases a slight degree of non-uniform gas distribution may not be resolved by the graphic analysis of the washout curve. It seems possible that in such cases calculation of the mean halftime and its standard deviation from the washout data (Van Liew, 1962, 1967) may show that the ratio S.D./ $x$ approaches that of a double exponential curve, or the nitrogen elimination of the slow component causes a deviation in the washout curve down to below $1 \%$. Excretion of tissue nitrogen and traces of nitrogen in inhaled oxygen make it very difficult to obtain a true curve at very low nitrogen concentrations.

Woolcock et al. (1969) have suggested that a fall of $\mathrm{C}_{\mathrm{dyn}}(1)$ to less than $80 \%$ of the static value at the high frequency might be considered peripheral airway obstruction. They reported such frequency-dependence in patients with obstructive lung disease but with nearly normal routine lung function data. However, we find a similar frequency-dependence, albeit less pronounced, in some healthy subjects. Our data also suggest that a decrease of dynamic lung compliance by more than $20 \%$ of the control value at a rate of 80 to 100 breaths per minute may be indicative of airway obstruction (Fig. 2), but this estimate is based on a small number of subjects.

Since Otis et al. (1956) did not find frequencydependence of dynamic lung compliance in six healthy subjects it has usually been assumed that frequency-dependence of compliance occurs only in diseased lung. Recently, Mead (1969b) pointed out that the time constant of the lung is so short compared to the period of a quiet breathing cycle that it should not be responsible for the distribution of ventilation. It seems that the data obtained in this study present evidence that the factors leading to non-uniformity of time constants are the same as those which cause non-uniformity of ventilation. Therefore, further study of the phenomenon in larger groups of adult healthy subjects, along with nitrogen washout curves to demonstrate the presence or absence of non-uniform gas distribution, appears necessary to settle this question. 
I wish to express my appreciation to Dr. Arend Bouhuys and to Dr. Hugh D. Van Liew for their critical review of the manuscript. I also wish to thank Mrs. Fenna G. Bouhuys for preparing the figures and Mrs. Carol Sadoski for typing the manuscript.

The experimental equipment used in this study was donated by the China Medical Board of New York, Inc., New York, N.Y. and the American Bureau for Medical Aid to China Inc., New York, N.Y.

\section{REFERENCES}

Albright, C. D., and Bondurant, S. (1965). Some effects of respiratory frequency on pulmonary mechanics. $J$. clin. Invest., 44, 1362.

Bouhuys, A. (1963). Pulmonary nitrogen clearance in relation to age in healthy males, J. appl. Physiol., 18, 297.

- Hagstam, K. E., and Lundin, G. (1956). Efficiency of pulmonary ventilation during rest and light exercise. Acta physiol. scand., 35, 289.

Briscoe, W. A., and Cournand, A. (1959). Uneven ventilation of normal and diseased lungs studied by an open-circuit method. J. appl. Physiol., 14, 284.

Butler, J., White, H. C., and Arnott, W. M. (1957). The pulmonary compliance in normal subjects. Clin. Sci., 16, 709.

Channin, E., and Tyler, J. (1962). Effect of increased breathing frequency on inspiratory resistance in emphysema. J. appl. Physiol., 17, 605.

Chiang, S. T., and Lyons, H. A. (1966). The effect of postural change on pulmonary compliance. Resp. Physiol., 1, 99.

Cumming, G., Crank, J., Horsfield, K., and Parker, I. (1966). Gaseous diffusion in the airways of the human lung. Resp. Physiol., 1, 58.

Darling, R. C., Cournand, A., and Richards, D. W. (1940). Studies on the intrapulmonary mixture of gases, III. An open circuit method for measuring residual air. J. clin. Invest., 19, 609.

Defares, J. G., and Donleben, P. G. (1960). Relationship between frequency-dependent compliance and unequal ventilation. J. appl. Physiol., 15, 166.

Ferris, B. G., and Smith, C. W. (1953). Maximum breathing capacity and vital capacity in female children and adolescents. Pediatrics 12, 341.

Fowler, W. S., Cornish, E. R., and Kety, S. S. (1952). Lung function studies. VIII. Analysis of alveolar ventilation by pulmonary nitrogen clearance curves. J. clin. Invest., 31, 40.

Frank, N. R., Mead, J., and Ferris, B. G., Jr. (1957). The mechanical behaviour of the lungs in healthy elderly persons. J. clin. Invest., 36, 1680.
Grimby, G., Takishima, T., Graham, W., Macklem, P., and Mead, J. (1968). Frequency dependence of flow resistance in patients with obstructive lung disease. $J$. clin. Invest., 47, 1455.

Ingram, R. H. Jr., and Schilder, D. P. (1968). Association of a decrease in dynamic compliance with a change in gas distribution. J. appl. Physiol., 23, 911.

Kory, R. C., Callahan, C., Boren, H. G., and Syner, J. C. (1961). The Veterans Administration-Army cooperative study of pulmonary function. 1. Clinical spirometry in normal men. Amer. J. Med., 30, 243.

Lyons, H. A., and Chiang, S. T. (1966). Specific compliance of pulmonary ventilatory compartments. Fed. Proc., 25, 201.

Mead, J. (1969a). Contribution of compliance of airways to frequency-dependent behaviour of lungs. $J$. appl. Physiol., 26, 670.

(1969b). The distribution of gas flow in lungs. In Circulatory and Respiratory Mass Transport: A Ciba Foundation Symposium, edited by G. E. W. Wolstenholme and J. Knight, p. 204. Churchill, London.

and Whittenberger, J. L. (1953). Physical properties of human lungs measured during spontaneous respiration. J. appl. Physiol., 5, 779.

Mills, R. J., Cumming, G., and Harris, P. (1963). Frequencydependent compliance at different levels of inspiration in normal adults. J. appl. Physiol., 18, 1061.

Otis, A. B., McKerrow, C. B., Bartlett, R. A., Mead, J., Mcllroy, M. B., Selverstone, N. J., and Radford, E. P. Jr. (1956). Mechanical factors in distribution of pulmonary ventilation. J. appl. Physiol., 8, 427.

Peslin, R., Saunier, C., Lacoste, J., and Sadoul, P. (1961). Variations de l'élastance pulmonaire en fonction de la fréquence respiratoire chez l'homme sain. $C$. $R$. Soc. Biol. (Paris), 155, 1106.

Takishima, T., Grimby, G., Graham, W., Knudson, R., Macklem, P. T., and Mead, J., (1967). Flow-volume curves during quiet breathing, maximal voluntary ventilation and forced vital capacities in patients with obstructive lung disease. Scand. J. resp. Dis., 48, 384.

Van Liew, H. D. (1962). Semilogarithmic plots of data which reflect a continuum of exponential processes. Science, 138, 682.

- (1967). Graphic analysis of aggregates of linear and exponential processes. J. theor. Biol., 16, 43.

Woolcock, A. J., Vincent, N. J., and Macklem, P. T. (1969). Frequency dependence of compliance as a test for obstruction in the small airways. J. clin. Invest., 48, 1097.

Zapletal, A., Motoyama, E. K., Van de Woestijne, K. P., Hunt, V. R., and Bouhuys, A. (1969). Maximal expiratory flow-volume curves and airway conductance in children and adolescents. J. appl. Physiol., 26, 308. 